\section{An Analysis of Spatial Equilibrium of Urban Land Use Case Study: Nowsud City \\ ${ }^{* 1}$ Masoud Taghvaei, ${ }^{2}$ Farzin Sayadi \\ ${ }^{1}$ Professor of Geography and Urban Planning, University of Isfahan \\ ${ }^{2} \mathrm{PhD}$ Student, Urban Planning, Isfahan (Khorasgan) Branch, Islamic Azad University, Isfahan, Iran \\ *Email: masoudtaghavii12@gmail.com}

\begin{abstract}
Today, spatial analysis is one of the important issues of urban planners and practices. The spatial equilibrium in the public services of city reflects a well-organized and desirable urban structure that has expanded the city's public services and utilities appropriately for the residents of the city. The city of Nowsud, one of the border towns of Iran with a population of about 1800 people and according to its sensitive regional situation, needs attention to the urban structure and the provision of public needs so that citizens will be satisfied with them and will require people to stay more in the city. The purpose of this paper is to examine how the level and per capita of the city's public services are distributed and supplied. Educational spaces, green spaces, cultural space, etc. are important elements in the formation of urban neighborhoods and its bone structure. The research method is development method in terms of purpose and is descriptive and analectic in terms of the value and in order to measure the spatial distribution of applications, Williamson coefficients and Shannon entropy models as well as GIS ARC software were used to provide more detailed maps and analyzes. The results of the research show that the city of Nowsud is composed of two old and new main neighborhoods in its spatial structure. The population of the old neighborhood is about onethird of the city's population, with a very high population density than the average of the city. But it should be noted that the placement of most public utilities and services in the new neighborhood is new so that so that the new neighborhood which is in the southern of the city, faces a surplus in per capita and the old neighborhood (the northern part of the city) faces with a huge shortage in per capita. Also, many land uses are not properly located due to their functional radius, which indicates the unfair spatial distribution of land uses as well as the inefficient spatial organization of this city, that finally, some suggestions have been presented to address it.
\end{abstract}

Keywords: Space Justice, Nowsud City, Williamson Coefficient, Shannon Entropy Model

\section{Introduction}

Today, economic and social inequalities are everincreasing phenomena (Lees, 2010: 1 \& UNDP, 2010), which have been taken into consideration since the early 1821s (Laurent, 2011: 263). In recent decades, one of the most important consequences of the accelerated growth of urbanization and the physical development of cities in the country has been the dismantling of the distribution system of service centers in the city, which has been the cause of social inequality of citizens in enjoying this service (Hatami Nejad, 2009: 71). This has made urban management not only difficult to provide public services but, in the era of globalization, has made efficient and effective management as a passive and contingent management (Varesi, 140: 2008). The concentration of service centers at a specific location, while creating bipolar and high and low areas in cities, causes an influx of consumer populations into these areas, so that on the one hand, environmental pressure, traffic, pollution, noise, air and so on. .., and on the other hand, due to the absorption of complementary, parallel applications, there is an intensification of spatial polarization in cities, in such a way that cities face drastic, unfavorable, and unsuitable environments with sustainable development (Khakpur, 187: 2009). Unfortunately, so far, the distribution of urban services has been more studied in the form of land use plans and per capita consumption criterion and there has been less importance for the accessibility of residents to urban services. While one of the main elements promoting the quality of the urban environment is the development of accessibility indicators, and optimal access is considered an essential factor for the success of the urban environment (Rahnama 137: 2006). In the city, justice along with three principles of efficiency, environmental quality and vitality are four major categories of urbanization (Saeid Nia, 2003:54). Justice is the concept of the distribution of functions, services and facilities, access to centers of service and activity (location of facilities), without discrimination and differentiation between residents of a city and urban areas (Behravan, 2006: 15). Public services are generally defined as economic activities that are 
public institutions. The foundation and setting them is under the control of public institutions, although public service is also provided for private sector investment (40, cho 2003). of course, obtaining public services on a large scale is directly affecting people's daily lives. Their responsibilities are with different and different authorities such as educational services, green space, sports, medical, cultural and religious services. These services all have spatial functions. The location of these centers, the radius of access, the access network, the spatial link with other services, and the scale of the supporting institutions, are their spatial characteristics (1978, 1978). The concept of accessibility from a variety of aspects is a broad concept, such as the physical, psychological, economic and financial accessibility that can be related to the nature of the land use and the transport network (Dadashpour and Rostami, 2011: 7). Accessibility is in fact the ability of the city's residents to have a good access to activities, resources, services, and the similar cases. Therefore, this concept is highly dependent on the city's spatial form, access network, type of travel, and form of travel (Lotfi, 2009:134). Public services must be easily accessible to them regardless of its spatial dimension, limitations and financial resources or physical capacity (: 22006 kaphle). The domination of capitalism on cities, on the one hand, and overemphasis on the planning process on the other hand, have led to urbanization in cities. This issue has brought many consequences for cities (Hilier, 2012, 1), the most important of which is the injustice of space and inequality in the distribution of services and resources in cities. The concept of justice is controversial and its definition depends on the time, place and political and social structures of society (Ashori, 2006,9). In the 1970s, the notion of justice in the distribution of resources and services was first introduced by David Harvey (neomarxist) (et al, 2010, 9 Tabibian) and in subsequent decades by researchers, including Rawls 1, Fanstein 2, Sandrak 3 Yong 4, Soja 5, Lucy 6, Talen 7, etc., were considered in urban planning (Rostami, 2011, 28-29). Few practical studies have focused on the equity of urban public

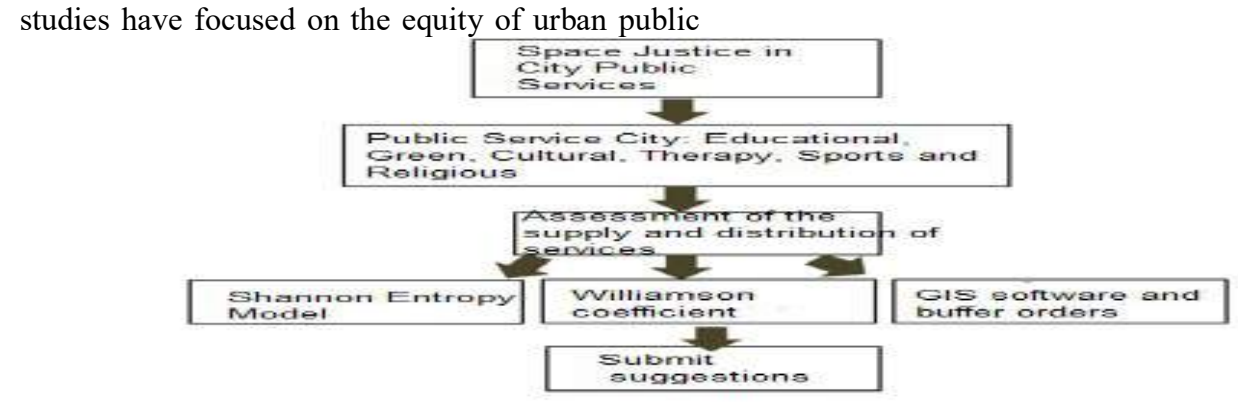

Graph 1 - Research Theoretical Framework facilities, which are more focused on a single type of facility (Tsou et al., 2005: 424).

David Harvey presented the essence of social justice to measure the equitable distribution of resources and services under three criteria. The necessity as the most important criterion, public benefit, and entitlement. Harvey argues that social justice in the city should be in a way that responds to the needs of urban populations. In his view, the concept of social justice ultimately means "fair distribution" (Harvey, 1997: 136 :). Regarding the fairness of service distribution planning, Corton and Wake recommend three basic principles: 1 . Prior to any service distribution, equality of opportunity should be recognized for all individuals. 2. Any deviation shall be supported if the most deprived persons benefit from this diversion. 3. There should always be a minimum level, in quantitative and qualitative terms, for the distribution of services and access to individuals, in such a way that individuals and services are placed at a higher level. The division, which Lucy (1981) and Krapton and Wick (1988) have used, and later used by Trolau (1993) and Marsh and Sklin (1994) and Thalen (1998) and others, are useful in this regard. These authors categorize justice in the distribution of resources and services in four ways, each of which alone or in combination can be a way to distribute fairly. These categories are: 1. Opportunity equality 2. Compensatory justice (Marsh and Schelin) or lack of justice (Lucy) 3. Accountability equal to demand (tastes and preferences in Lucy's classification) 4. Follow the market system (Power Payment in Lucy's category) (Cho 2003: 40).

The Theoretical Framework of Research

The theoretical framework of the research includes the process of doing the work and the methods and models are presented below:

\section{Research Purposes}

1. Review of Spatial equilibrium in the city of Nowsud and how to supply and distribute the uses of public city.

2. Equilibrium strategies for urban services 


\section{Case Study: Nowsud}

Nowsud is one of the cities of Kermanshah province in western Iran. This city is the center of the Nowsud district of Paveh city. The distance from Nowsud to Paveh is about $35 \mathrm{~km}$ and is located in the northwest. 80 years ago, the small town of Nowsud was headed by Ja'far Soltan (one of the Uraman clerks). Nawsud people speak Kandyarāmi dialect. Noosud was occupied by the Iraqi army in February 1979 and was freed from the Iraqi people on March 24, 1986 (Bakhtiari, 2004). The municipality of Nowsud as established in 1955

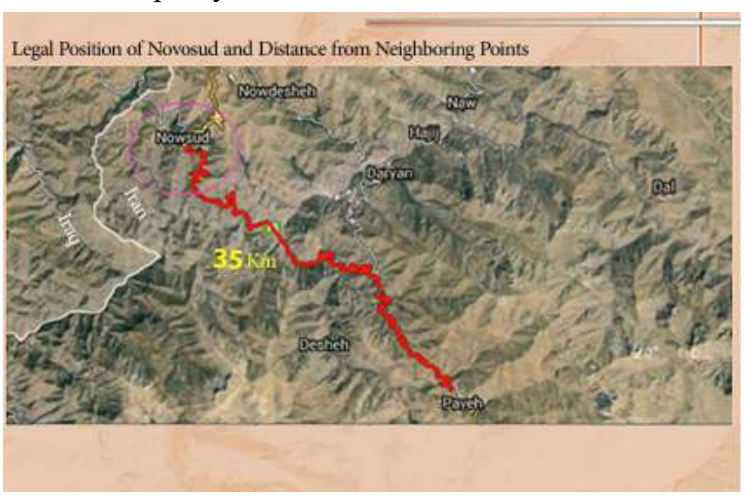

and this settlement has since been known as the city. Prior to the establishment of the municipality, this settlement was one of the villages of the Paveh city, established in 1337 as the city of Paveh and Oramanath. The features of this city are very rugged and steep topographic position, close proximity to the border, the high capacity of tourism-nature, the high level of employment in the service sector, the role of the city in providing commercial services and tourism to Iraqi Kurdistan ... (Consultant Engineers of Mad-Shar Zagros, 2016)

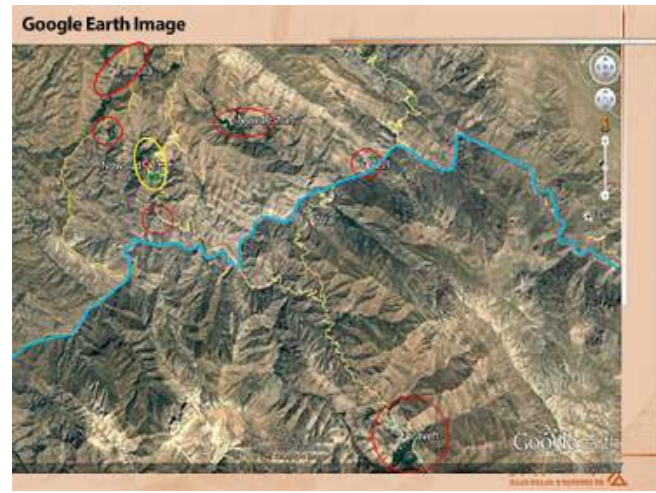

\section{Map 1 - Location of Kermanshah Province, Pave City, \& the City of Noosdat Makhz: Master Plan in 2016}

According to the census data of 2011, the population of the city of Nowsud was 1,730 in the form of 550 households and based on the province's management and planning authority in 2015, the city of Nowsud has a population of 1,800 . The literacy rate in the city was 80.6 percent in this year, that a literacy rate among women and men was (74.4 percent) and ( 86.2 percent). Lack of job opportunities is one of the main factors of immigration, especially among educated youth. The general features of this city are listed in the table below.

\begin{tabular}{|c|c|c|c|c|c|c|c|}
\hline \multirow{3}{*}{ Use Name } & \multirow{2}{*}{\multicolumn{3}{|c|}{$\begin{array}{c}\text { Population of Current Status } \\
\text { Year 2015: 1,800 People }\end{array}$}} & \multirow{2}{*}{\multicolumn{3}{|c|}{$\begin{array}{c}\text { Proposed Population } \\
\text { Year 2025: } 2419 \text { People }\end{array}$}} & \multirow{3}{*}{$\begin{array}{c}\text { Increase or } \\
\text { Decrease } \\
\text { Levels }\end{array}$} \\
\hline & & & & & & & \\
\hline & Area & Per Capita & Percent & Area & Per Capita & Percent & \\
\hline Residential & 62362 & 34.6 & 21.5 & 116116 & 48 & 29.5 & 53754 \\
\hline Commercial Service & 6814 & 3.8 & 2.3 & 9671 & 4 & 2.5 & 2857 \\
\hline Educational & 8368 & 4.6 & 2.9 & 12137 & 5 & 3.1 & 3769 \\
\hline Therapy & 2139 & 1.2 & 0.7 & 3074 & 1.3 & 0.8 & 935 \\
\hline Administrative and Law Enforcement & 14511 & 8.1 & 5 & 17659 & 7.3 & 4.5 & 3148 \\
\hline Religious & 944 & 0.5 & 0.3 & 1716 & 0.7 & 0.4 & 772 \\
\hline Cultural and Artistic & 4316 & 2.4 & 1.5 & 4912 & 2 & 1.2 & 596 \\
\hline Sport & 4804 & 2.7 & 1.7 & 10729 & 4.4 & 2.7 & 5925 \\
\hline Recreational Tourist & 1780 & 1 & 0.6 & 11479 & 4.7 & 2.9 & 9699 \\
\hline Urban Equipment & 5092 & 2.8 & 1.8 & 5590 & 2.3 & 1.4 & 498 \\
\hline Urban Facilities & 1190 & 0.7 & 0.4 & 1174 & 0.5 & 0.3 & 16- \\
\hline Transportation and Warehouses & 5240 & 2.9 & 1.8 & 11218 & 4.6 & 2.9 & 5978 \\
\hline Transit Network & 97196 & 54 & 33.5 & 128307 & 53 & 32.6 & 31111 \\
\hline Industrial & 454 & 0.3 & 0.2 & 4010 & 1.7 & 1 & 3556 \\
\hline Green Space and Park & 8215 & 4.6 & 2.8 & 31108 & 12.9 & 7.9 & 22893 \\
\hline Garden and Crops & 14531 & 8.1 & 5 & 17897 & 7.4 & 4.6 & 3366 \\
\hline Not Built Land & 52561 & 29.2 & 18.1 & 0 & 0 & 0 & $52561-$ \\
\hline Pedestrian Pavement & 0 & 0 & 0 & 4270 & 1.8 & 1.1 & 4270 \\
\hline Additional Land for Adjacent Land Use & 0 & 0 & 0 & 2055 & 0.8 & 0.5 & 2055 \\
\hline Total & 290517 & 161.4 & 100 & 393122 & 162.5 & 100 & 102605 \\
\hline
\end{tabular}

Table 1 - General Features of Nowsud City 


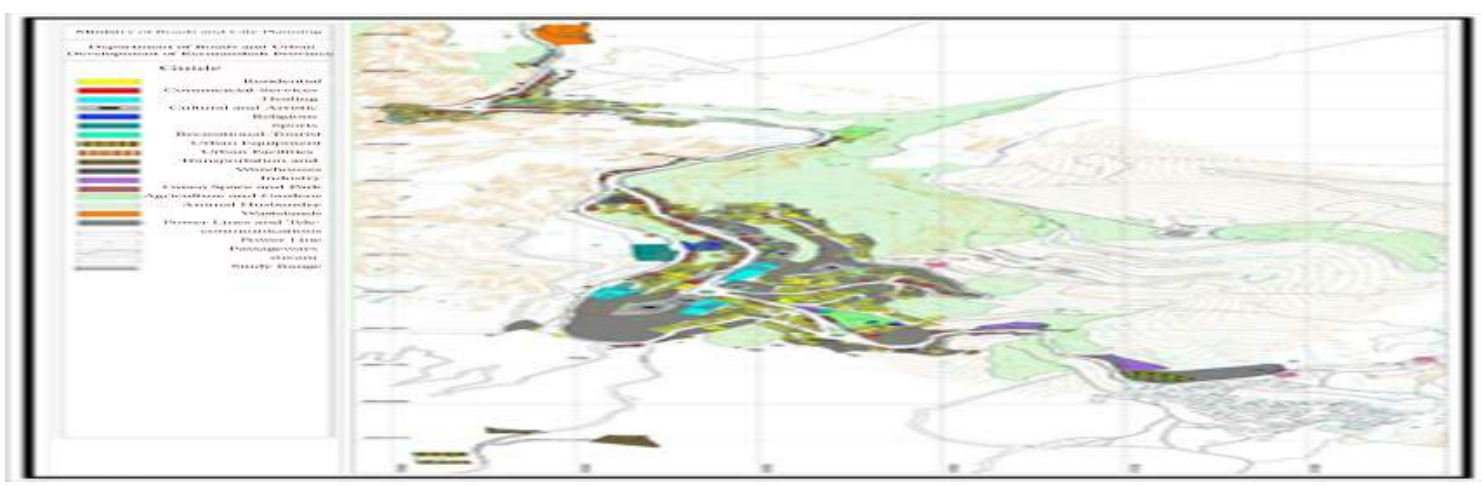

Map 2: Land Use of Current Status of the City of Nowsud Reference: Master Plan 2016

Investigation the Spatial Equilibrium in Distribution and Provision of Public Utilities Per Capita of City

In the study of spatial justice and distribution of services in the city, first, using the Williamson coefficient, which is an index that indicates the degree of dispersion of a balanced distribution and the provision of an indicator in different regions,(Ebrahimzadeh et al 2010) public services in the city in different fields has been studied.

Then, the approach of dispersion and distribution of public services through an entropy coefficient model has been assessed and then for more favorable spatial visibility than the current situation of the city in its neighborhoods, based on their land use, their access radius and their threshold population in the GIS environment, buffers have been created and we will see the city's spatial view and the establishment of services in urban neighborhoods. Then, based on the per capita situation in the neighborhoods, the surpluses and shortages of different land uses have been determined and the proposed area has been set according to the city's per capita standard.

\section{Williamson Index}

The Williamson Index is one of the indicators in the study of the spatial distribution of services in different parts of the city. Williamson (1965), in the field of regional discussions, is the first to generalize income disparity issues to regions (Tadjoeddin, 2003). In this research, the ranking of neighborhoods in the city of Nowsud has been presented in the provision of services based on the Williamson index for public services in the city. Williamson's index is:

In this formula, $\mathrm{n}$ is the number of regions, $\mathrm{Xi}$ per capita of the index in $\mathrm{i}$, Xn per capita, the target index in the whole city, $\mathrm{Pi}$ is the population of the region $\mathrm{i}$ and $\mathrm{N}$ is the total population of the city
(Tadjoeddin 2003,2). This index is between zero and one. The resulting figure tends to be zero, indicating the reduction of inequalities (Hikmat Nia 2006,261).

$$
V_{i}=\left(\sqrt{\sum_{i=1}^{n}\left(x_{\left.i-x n) \frac{P_{i}}{N}\right)}\right.}\right) / X_{n}
$$

The Williamson index is located in the city and in dual city neighborhoods, in all types of utilities. It can be seen that in general, in the city, the greatest inequality and imbalance is in the level of provision and per capita services such as health, religious and cultural services, as Williamson's index is very close to 1 in these three domains. Also, in the study of urban neighborhoods, it can be seen that in the commercial sphere, both neighborhoods have been relatively interested, and the Williamson index is closer to zero than other domains. Also, in the field of green space, this is true. In the cultural and religious sphere, there is an inequality in the provision of services. It is also seen that, especially in the old neighborhood of the city, we face a surplus of religious per capita.

In the educational area, as in the following, the old neighborhood of the city has no educational land use and, with the population of about 600 people, does not have the minimum criteria. While the new neighborhood has been provided for this per capita. Table numbers illustrate the current situation, so that the coefficient checked in the new neighborhood tends to zero.

In the chart below, the Williamson coefficient is shown in two different neighborhoods in different land uses. 


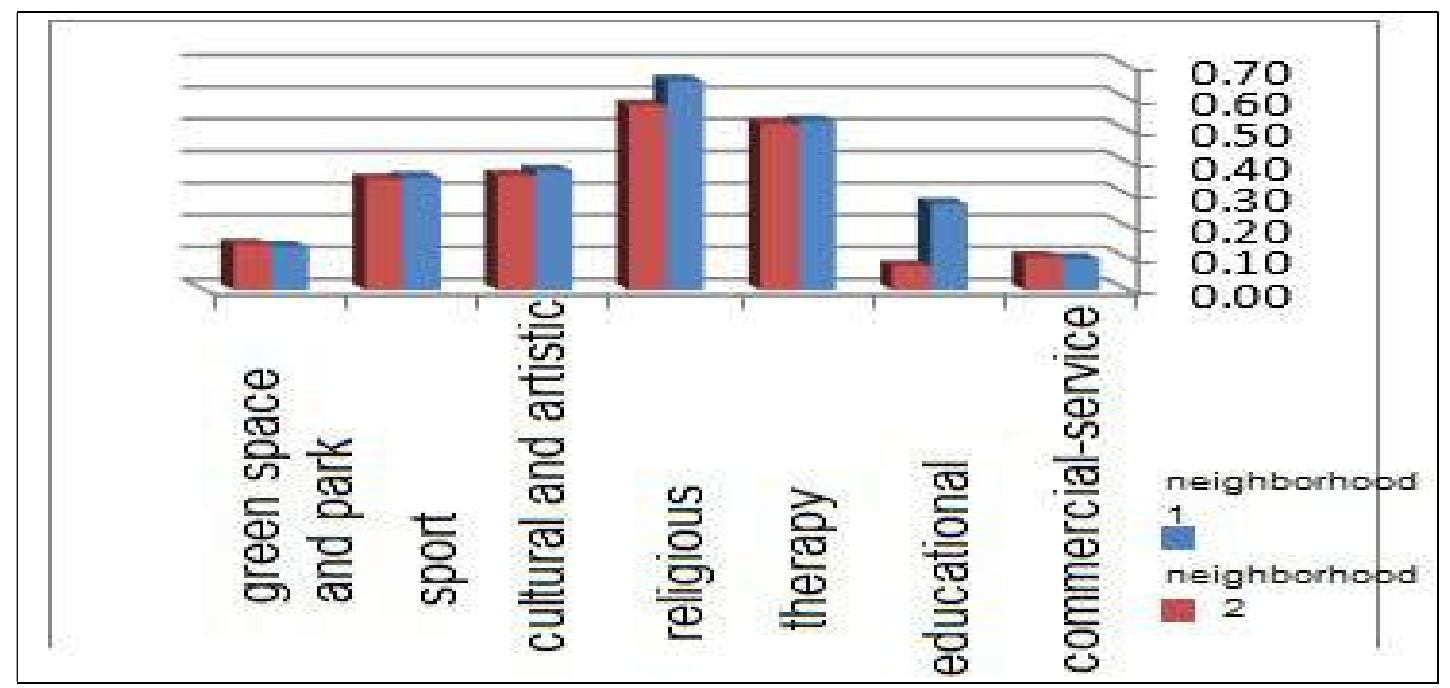

Graph 2 - Williamson Coefficient in Different Places of the City: Author

\begin{tabular}{|l|l|l|l|}
\hline Land Use & City & $\begin{array}{l}\text { Neighborhood 1 } \\
\text { (Old Neighborhood) }\end{array}$ & $\begin{array}{l}\text { Neighborhood 2 } \\
\text { (New Neighborhood) }\end{array}$ \\
\hline Commercial & 0.14 & 0.1 & 0.1 \\
\hline Educational & 0.28 & 0.27 & 0.07 \\
\hline Sanitary-Clinical & 0.74 & 0.53 & 0.22 \\
\hline Religious & 0.87 & 0.65 & 0.58 \\
\hline Cultural & 0.52 & 0.37 & 0.36 \\
\hline Sport & 0.49 & 0.35 & 0.35 \\
\hline Green Space & 0.2 & 0.14 & 0.14 \\
\hline
\end{tabular}

Table 2 - Williamson Index for Different Land Uses and in Urban Neighborhoods

\section{Entropy Coefficient}

An entropy model can be used to measure the uniformity of the desired variables, such as the distribution of city population or public services. According to the theoretical model of the model, when the entropy approaches a number of one, the sign of the existence of the equilibrium and the spatial equilibrium of one variable is observed and below that number indicates the vice versa (Varesi, 2008,152). Using this model, we can determine the spatial equilibrium of population deployment, services, etc. at the level of the urban, regional or national network.

$$
\begin{aligned}
& H=-\sum P i L n P i \\
& G=H / \operatorname{LnK}
\end{aligned}
$$

In this formula, $\mathrm{H}$ is the sum of the frequency of non-linear logarithms, the frequency of $\mathrm{Pi}$, the $\mathrm{LnPi}$

of the nonparbing logarithm, $\mathrm{K}$ is the number of classes, and $\mathrm{G}$ is the amount of entropy (Hekmat Nia and Mousavi, 2006, 189).

The entropy coefficient obtained shows a very unfavorable situation in the distribution of urban public utilities. In the review of types of usage, it is seen that the imbalance in the distribution of services is so common that entropy figures are zero. This is due to the overwhelming accumulation of public utilities in the new neighborhood and the depriving of the old neighborhood of public utilities, which has been well documented in entropy measurements. Religious and green space among other land uses has a good status and is distributed in both the old and new neighborhoods. In the following, the status of land uses and the location of their establishment in the neighborhoods, confirms the obtained results in this section.

\begin{tabular}{|l|c|c|}
\hline Uses & $H=-\sum$ PiLnPi & $\mathrm{G}$ \\
\hline Educational & 0 & 0 \\
\hline Sanitary-Therapy & 0 & 0 \\
\hline Religious & 0.67 & 0.97 \\
\hline Cultural & 0 & 0 \\
\hline Sport & 0 & 0 \\
\hline Green space & 0.69 & 1 \\
\hline
\end{tabular}

Table 3 - Calculation of the Entropy Coefficient of Urban Services at the Urban Levels; Source: Author 
Measurement of the Situation of Land Uses Per Capita in the Urban Neighborhoods and Their Distribution and Location using GIS Software In analyzing the distribution situation and providing land use per capita, the city was measured in two areas of the old neighborhood and the new neighborhood. So the area of the important uses was determined, their per capita were specified, their available access radius was by the buffer method, and finally, the intervals and distances of land uses are estimated from each other that

Table 4 - The Appropriate Approach to Dissemination of Service Use in the City. Reference: Writer

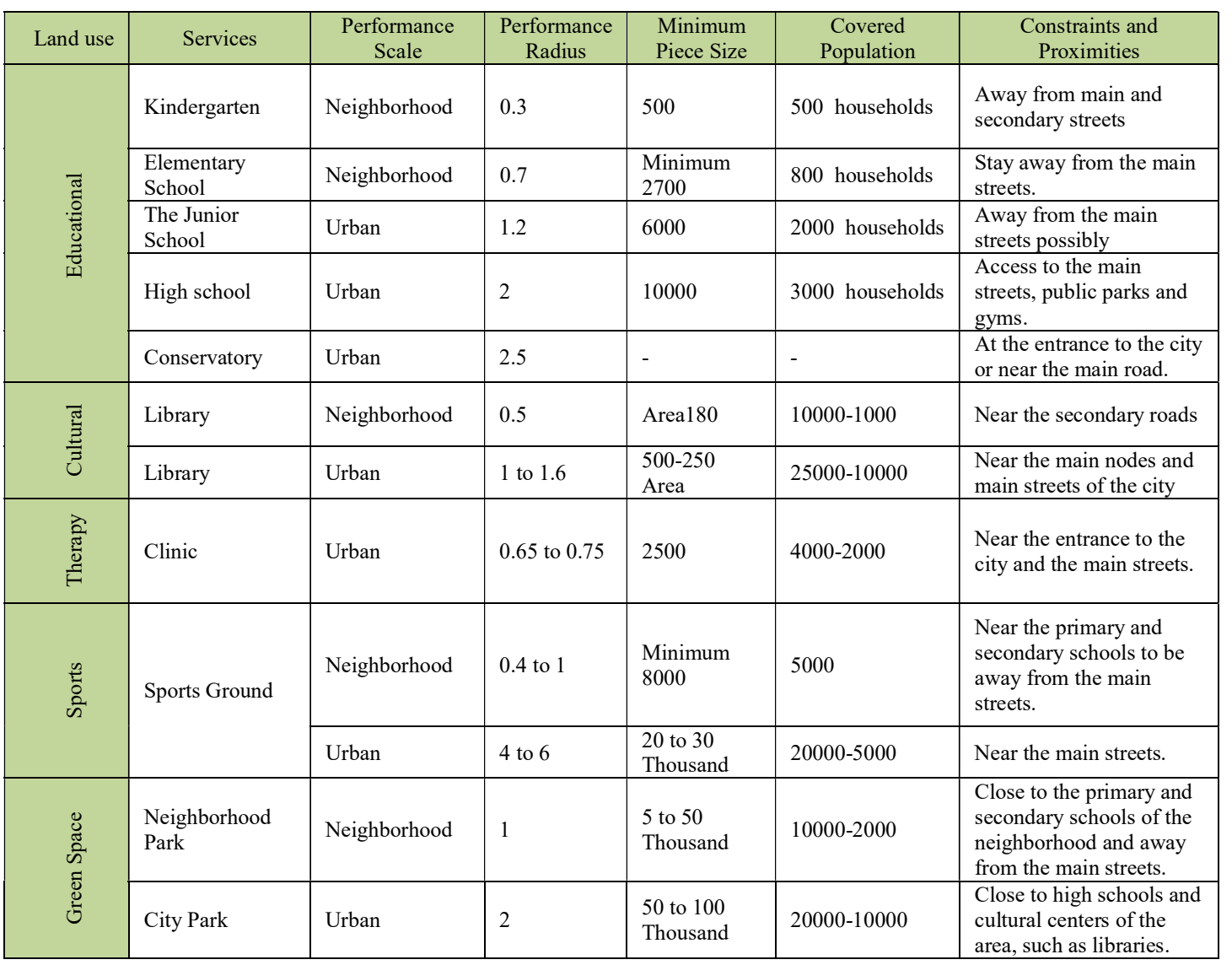

indicates their distribution in the city and among its two main neighborhoods. Also, the two neighborhoods of the city are separated by two distinct black and green colors to illustrate how the distribution and diffusion of land uses between the two neighborhoods are well represented. It is worth noting that the access radius and the minimum areas necessary for residential and urban land use are given in the table below, which is used to carry out the study: 
Helix Vol. 8(4): 3572- 3582

\begin{tabular}{|c|c|}
\hline Descriptions & Location Map and Land Use Distances \\
\hline $\begin{array}{l}\text { Elementary School Land Uses } \\
\text { Following maps are based on the type of land use } \\
\text { placement at the neighborhood level, their } \\
\text { relationship and their distance with each other, the } \\
\text { way of placing in new and old neighborhoods } \\
\text { marked with two distinct colors. } \\
\text { In examining the status of the primary school, it can } \\
\text { be seen that in the city, two primary schools are } \\
\text { located at a distance of } 181 \text { meters from each other, } \\
\text { both in the new neighborhood and very much close } \\
\text { to the main direction of the city, so that their } \\
\text { functional radius did not completely cover the city's } \\
\text { old boundaries and were not properly distributed at } \\
\text { the new neighborhood level. } \\
\text { Investigation of per capita shows that the new } \\
\text { neighborhood has a per capita surplus and the old } \\
\text { neighborhood has zero per capita. Also, according to } \\
\text { the previous table, the land use of the elementary } \\
\text { school should be away from the main roads of the } \\
\text { city, which unfortunately has not been observed in } \\
\text { the city. } \\
\text { It is worth noting that the city does not have } \\
\text { preschool land use. }\end{array}$ & 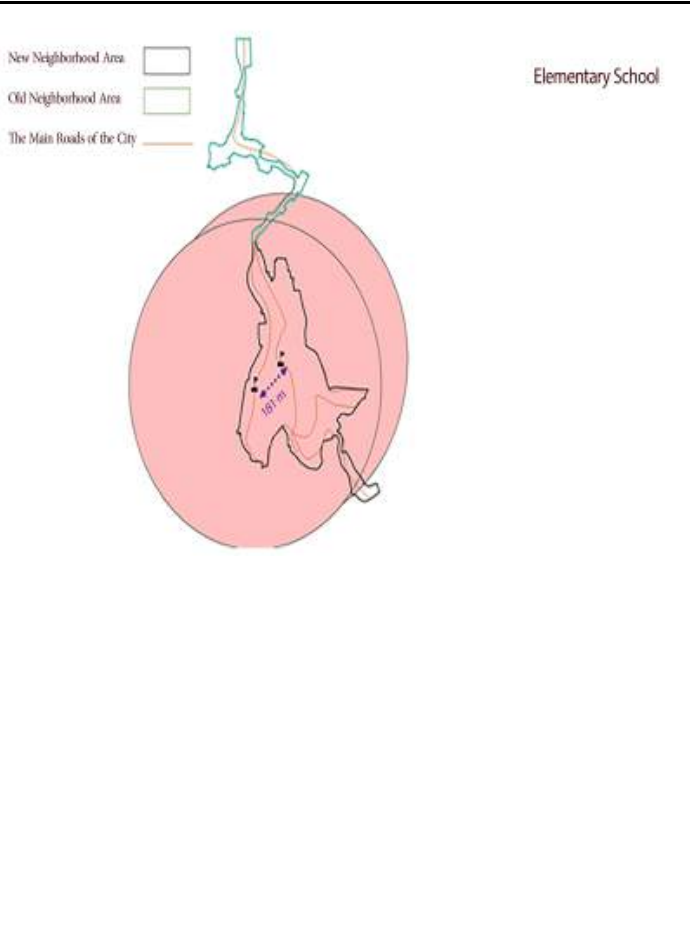 \\
\hline \multicolumn{2}{|c|}{ High School Land Use } \\
\hline Second Turn of High School & First Turn of High School \\
\hline $\begin{array}{l}\text { At the city level, high school land use is in two turns, } \\
\text { seen that the first and second high schools, which hav } \\
\text { old neighborhood has been deprived from this land us } \\
\text { main roads, while according to the criteria, it is better } \\
\text { functional radius of these uses, except for a small part } \\
\text { the city }\end{array}$ & $\begin{array}{l}\text { which both are located at a specific location. It can be } \\
4 \text { high schools, are in the new neighborhood and the } \\
\text {. High school land uses are usually away from the } \\
\text { to access the main roads and parks. It is seen that the } \\
\text { of the northern area of the old neighborhood, covers }\end{array}$ \\
\hline
\end{tabular}


Helix Vol. 8(4): 3572- 3582

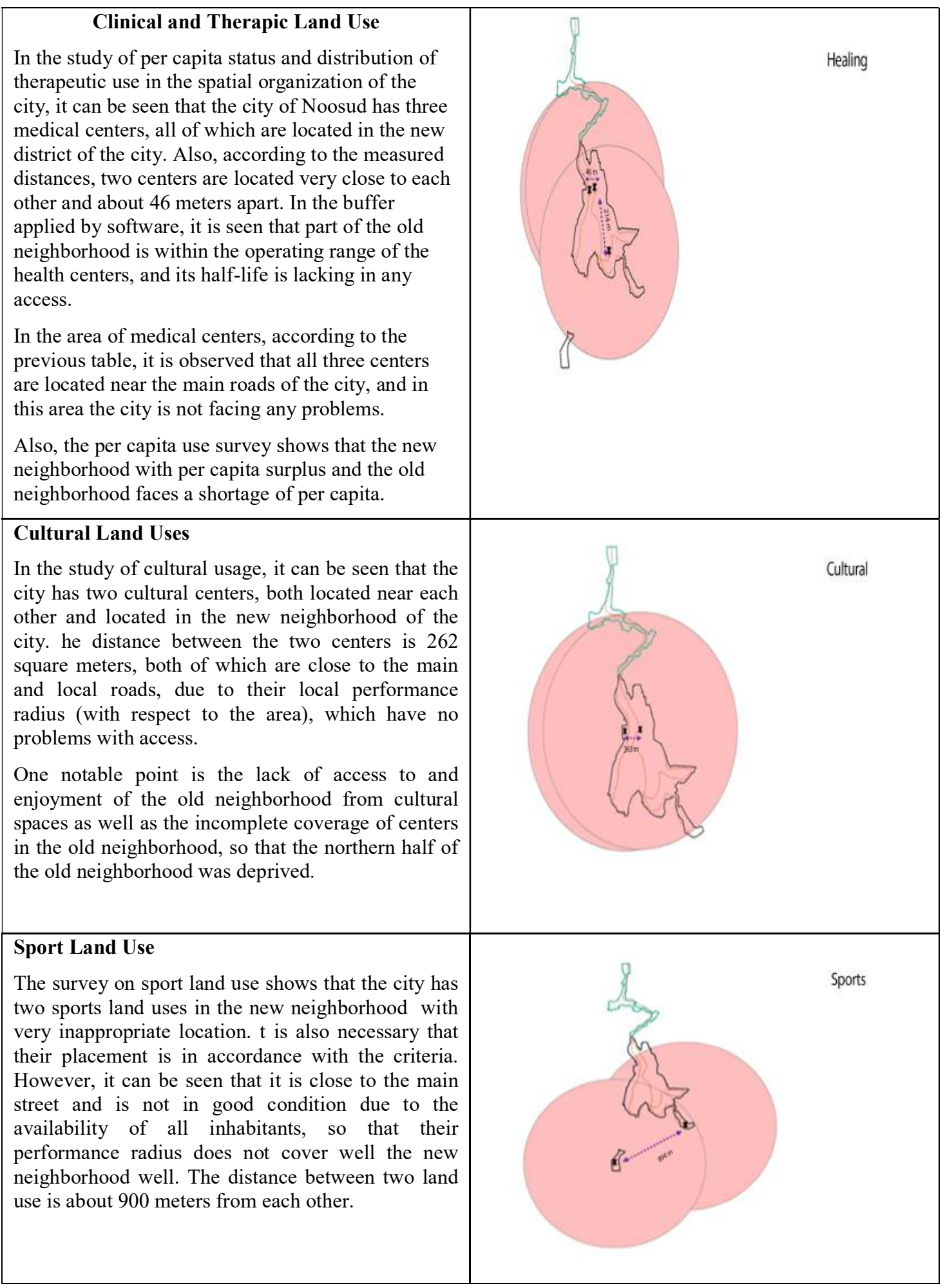




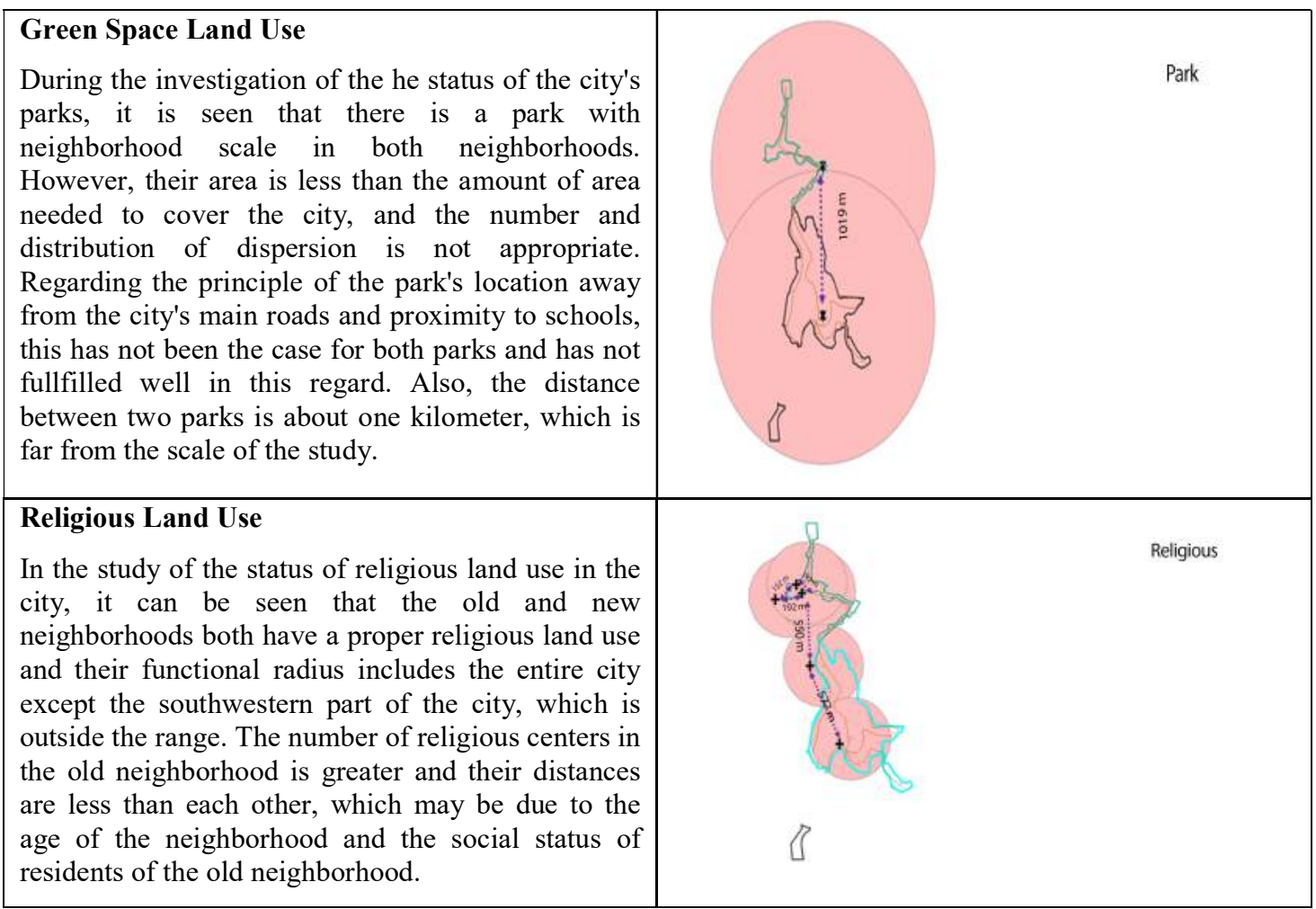

Map 3 to 10- Land Use, Dispersion (Access Radius) and Different Usage Distances in the City and Neighborhoods According to the Mentioned Topics. Reference: Writer

The survey of the area and per capita land use of new and old neighborhoods in the following table is presented in the following way: it is possible to compare and find the most important problems and inequalities in the distribution and supply of services per capita. It can be seen that in many land uses, the old neighborhood is struggling with the problem of the lack of space and per capita, while the new neighborhood of city, except in the preschool area, which is not available in the city, faces with surplus in area and per capita and it confirms the lack of proper distribution of space, as well as providing appropriate area and per capita utilization in the city and paying more attention to meeting the needs of residents of the newer urban area. It is worth noting that the standard per capita based on the proposed per capita of the city's detailed plan is presented in this table.

Table 5 - The Area and Per Capita of Existing Land Uses Compared to the Standards: Writer

\begin{tabular}{|c|c|c|c|c|c|}
\hline \multirow{2}{*}{ Land Use } & \multirow{2}{*}{ Neighborhoods } & \multirow{2}{*}{ Standard Area $\left(\mathrm{m}^{2}\right)$} & \multirow{2}{*}{ Standard Per Capita } & \multirow{2}{*}{$\begin{array}{l}\text { Standard } \\
\text { Area }\left(\mathrm{m}^{2}\right)\end{array}$} & $\begin{array}{l}\text { Existing and Standard Per } \\
\text { Capita Differences }\end{array}$ \\
\hline & & & & & - Surplus + and Shortage \\
\hline \multirow{2}{*}{ Preschool } & Old Neighborhood & 0 & \multirow{2}{*}{0.4} & 240 & $240-$ \\
\hline & New Neighborhood & 0 & & 480 & $480-$ \\
\hline \multirow{2}{*}{$\begin{array}{c}\text { Elementary } \\
\text { School }\end{array}$} & Old Neighborhood & 0 & \multirow{2}{*}{0.8} & 480 & - \\
\hline & New Neighborhood & 2494 & & 960 & $1534+$ \\
\hline \multirow{2}{*}{ High School } & Old Neighborhood & 0 & \multirow{2}{*}{0.7} & 420 & $420-$ \\
\hline & New Neighborhood & 3237 & & 840 & $2397+$ \\
\hline \multirow{2}{*}{ Commercial } & Old Neighborhood & 2527 & \multirow{2}{*}{0.5} & 300 & $2227+$ \\
\hline & New Neighborhood & 4287 & & 600 & $3687+$ \\
\hline \multirow{2}{*}{ Sport } & Old Neighborhood & 0 & \multirow{2}{*}{0.5} & 300 & $300-$ \\
\hline & New Neighborhood & 4804 & & 600 & $4204+$ \\
\hline \multirow{2}{*}{ Therapy } & Old Neighborhood & 0 & \multirow{2}{*}{0.5} & 300 & $300-$ \\
\hline & New Neighborhood & 2139 & & 600 & $1539+$ \\
\hline \multirow{2}{*}{ Park } & Old Neighborhood & 3457 & \multirow{2}{*}{3} & 1800 & $1657+$ \\
\hline & New Neighborhood & 4758 & & 3600 & $1158+$ \\
\hline \multirow[t]{2}{*}{ Regional } & Old Neighborhood & 492 & \multirow[t]{2}{*}{0.1} & 60 & $432+$ \\
\hline & New Neighborhood & 451 & & 120 & $331+$ \\
\hline \multirow{2}{*}{ Cultural } & Old Neighborhood & 0 & \multirow{2}{*}{1.7} & 1020 & $1020-$ \\
\hline & New Neighborhood & 4316 & & 2040 & $2276+$ \\
\hline
\end{tabular}




\section{Conclusions and Suggestions}

According to the distribution and location of important land uses of the city as well as the problem of providing their area and per capita in the city of Nowsud, which is a small and frontier city and which requires a lot of attention from the government, it is concluded that the city suffered from many in spatial injustice to provide and distribute the city's public utilities, so that the northern part of the city, which is in line with the old neighborhood of the city, is neglected and many of the urban uses in the southern neighborhood of the city, or the newer neighborhoods with a surplus per capita, are lagging behind in this area and Proposals and suggestions for the fair provision of service land use as well as improvement of the spatial organization of the city are listed below, which we hope they will be considered in future plans and programs in order to some extent to overcome some of the city's physical and social problems. The general part of all suggestions is to provide level and per capita of land uses that are considered as part of the city's public utilities and need to be more appropriately distributed.

- Establishment of cultural centers by providing level and per capita as well as appropriate and compatible distribution with the culture of urban residents in the urban neighborhoods.

- Establishment of preschool centers with the fulfillment of the rules for the provision of per capita income, as well as layout rules covering the whole city and its neighborhoods.

- Establishment of the elementary school land use in the old neighborhood with the provision of per capita of neighborhood and location criteria.

- Provision and location appropriate green space and establish a link between green spaces of neighborhoods, preschools and preschools by meeting the criteria such as avoiding major roads and

- Establishment of health centers in the old neighborhood, meeting the criteria of location, access and per capita.

- Reducing the level of uses with surplus per capita or mixing them into other land uses to supply other uses, such as cultural and religious mixing land uses.

- Establishment of a sports complex in the old neighborhood and modification of the existing centers in the new neighborhood.

\section{References}

1- Ismail Zadeh, Hasan and Zahra Afzali Group. (2015). Optimal strategy for the realization of spatial justice. Demographic and urban services utilization using a hybrid model (Case study: Bonab city). Quarterly Urban Planning Studies. third year. No. 11

2- Behravan, Hossein 2007. Cultural and Urban Justice survey in the Twelve Areas of Mashhad Municipality, Conference on Urban Management and Planning, Proceedings. first volume. Mashhad.

3- Taqvaei Masoud and Shafaqi Sirous and GhaderI Mohammad Reza (2016) Investigating the Effective Factors on Equilibrium in the Space Field of Guilan Province Quarterly Journal of the Land Volume 8, Issue 1, Spring-Summer 2016Pages 83 to 105 .

4- Taqvaei Masoud and Azani Mehri and Tirband Majid (2015) Establishment of insecurity in public spaces in the case of Yasuj city. Journal of crime prevention studies (Scientific-Promotion). Year 10, No. 35, Summer 2015, Page 47 to 66.

5- Taqvaei Masoud and Ghaioumi Hamid Mohammadi and Nasiri Yousef (2013) Spatial Analysis of Physical Development of Eghlid City Using AHP Method. Quarterly Journal of Geographic Research. Vol. 28 No. 3, Autumn 2013 Number of Series: 110 Pages 31 to 52 .

6- Taqvaei Masoud and Ahmadian Mehdi and Ali zadeh, Jaber (2012). Spatial Analysis and Development Measurement of the Misandhab County Villages Using the Topsis Model. Quarterly Journal of Environment No.21, 2012. Page 19 to 35.

7- Roustaei, Shahrivar. Babaei, Eli Naz and Zahra Kamali Far. (2015). Evaluating spatial justice in the distribution of urban services. Case study: Tabriz Metropolis. Geography Space Magazine. third year. 8- Rahnama, Mohammad Rahim, Liz, Anna, 2006, Measurement of Accessibility Change in the City of Sydney, Geography and Development Magazine. number 7

9- Dadashpour, Hashem. Rostami, Faramarz. (2011). Analysis and distribution of urban public services from the point of view of spatial justice (Case study: Yasuj city). Geography and Regional Development Magazine. Number sixteen

10- Hataminejad, Hossein, Farhoudi, Rahmatullah and Morteza Mohammad Pourjabi, 1999, Analysis of Social Inequality in Utilizing Urban Services Case Study: Esfarayen City, Human Resource Research, No. 65, p. 71-85, Autumn 1999, Tehran.

11- Habibi, Kiomars. Alizadeh, Houshmand. Moradi Masihi Varaz, Voldabegi, Siwan and Sasan Vafaiy (2011). Analysis and analysis of the social justice situation in the spatial structure of Sanandaj. Urantia Quarterly. number 7.

12- Khakpour, 2009, Measurement of Inequality in Developmental Levels in Mashhad, Science and Development, No. 27, Mashhad: 2009

13- Saeednia, Ahmad 1999 Urban land use Green Book of Municipalities, Volume II, Tehran. 
Helix Vol. 8(4): 3572- 3582

Publications of the Municipal and Rural Municipality Organization.

14- Management and Planning Organization of the province (2016)

15- Ghatami, Mostafa, Lotfi, Sadagheh, and Kokab Khaleghnia. (2013). Investigating the Effect of Spatial Policies on Urban Space Structure with Emphasis on Construction Concentration Case Study: Tehran. Urban Studies Quarterly. No. 6.

16- Madshar Zagros Consulting Engineers. (2016). Comprehensive and detailed plan of the city of Nowsud. Department of Roads and Urban Development of Kermanshah Province.

17- Varesi, Hamid Reza. Mohammadi, Jamal and Ahmad Shahindi. (2008). Locating Urban Green Space Using Geographic Information (Case Study: Khorram Abad City). Geography and Regional Development Magazine. Number tenth.

18-Ashori, Mohammad. (2006), Human Rights,Equality, Fairness and Justice, The FacultyOf Law And Political Science Press, Tehran University

19-Chang, H-S and Liao, C-H. (2011). Exploring an integrated method for measuring the relative spatial equity in public facilities in te context of urban parks, cities, 04.002. 1-11

20-Cho, Chun Man.(2003). Study on effects of resident-perceived neighborhood boundaries on public services: Accessibility \& its relation to utilization: Using Geographic Information System focusing on the case of public parks in Austin, Texas, Texas A\&M University.

21-Dadashpoor, H., Rostami, F. (2011). Measurement of Integrated Index of Spatial Justice in the Distribution of Urban Public Services Based on Population Distribution, Accessibility and Efficiency

22-Yasuj City, Journal of Regional and Urban Researches and Studies, Tehran, 4, 1-22.Dai F. C., Lee, C. F. and Zhang X. H. (2001). GISbased geoenvironmental evaluation for urban land-use planning. Engineering Geology, 61(4), 257-271.

23-Dufaux, Frederic.(2008), Birth announcement,justice spatial/spatial justice, www.jssj.org.

24-Harvey, D. (1998), Social Justice and the City, Tehran: Urban Planning Publishing C 